\title{
The Journal of Human Hypertension becomes the official journal of the British and Irish Hypertension Society
}

\author{
Francesco P. Cappuccio ${ }^{1}$
}

Received: 22 January 2019 / Accepted: 22 January 2019

c) Springer Nature Limited 2019

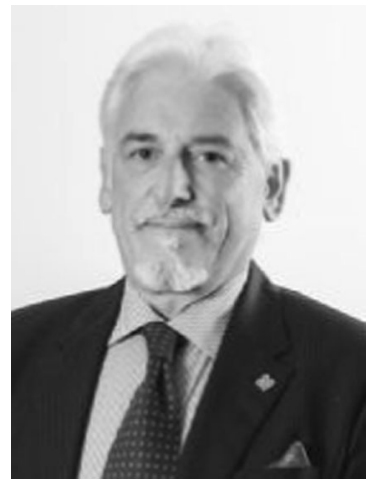

Dear Readers of the JHH, Members and Fellows of the BIHS, I am happy to announce that, as from March 2019, the Journal of Human Hypertension becomes the official journal of the British and Irish Hypertension Society. This partnership brings together two organisations that have been at the forefront of hypertension and cardiovascular research, making some important landmark advances globally.

The British Hypertension Society (later British and Irish Hypertension Society) was founded in 1981 and plays an important role in the national and international scene of hypertension and cardiovascular research, education, training and advocacy. It shall be of no surprise to some to learn that the impetus to found a new journal in the field of hypertension in 1987 came from within the British Hypertension Society as an "expression of irritation on the part of many clinicians on the domination of the hypertension literature by papers on molecules and laboratory animals" [1]. While not underrating the importance of basic science, it was a recognition of the growing importance of hypertension as a clinical sub-specialty and the need to encourage and disseminate clinical and epidemiological research on the subject, accepting a't times "documented clinical enquiry", opening access to other health professionals (nurses as an example), whose contribution in the care of patients with hypertension was destined to play a major role [2]. The first Editor was Gareth Beevers, to whom most of us should be forever grateful. He led the Journal for many years aided by Franz Messerli and Hirotsugu Ueshima, to testify the Journal's international outlook. Their vision, determination and resilience made it possible that we have

$\triangle$ Francesco P. Cappuccio

F.P.Cappuccio@warwick.ac.uk

1 President of the British and Irish Hypertension Society, University of Warwick, Warwick Medical School, and UHCW NHS Trust, Coventry, UK now a highly respected scientific journal, part of the Nature Publishing Group, which still thrives in its 32nd year of existence. With time naturally things have evolved, and the Journal is now led by a renewed esteemed, international panel of Editors and members of the Editorial board [3].

The special relationship between the BIHS and the Journal has been maintained over the years with the annual publication of the abstracts of the BIHS Annual Scientific Meeting since the Journal was founded. This will continue in the years to come. The current decision to strengthen the partnership will add more to the special link between the two organisations and will offer reciprocal benefits. Our Members and Fellows will receive an on-line subscription to the Journal as part of their membership fees, with an option to buy the printed version for a small extra fee. The BIHS will be the only scientific society represented by the Journal. Both the Journal's and the Society's websites will share links to disseminate information of reciprocal interest. The Journal shall offer a regular space for the publication (still peer-reviewed) of BIHS short statements or points of discussion. In addition, there will be the opportunity to publish up to four open access manuscripts (subject to peerreview) "on behalf of the BIHS", such as guidance, endorsement, statements, commentaries etc.

On behalf to the Executive Committee of the British and Irish Hypertension Society, I welcome you all to this partnership and encourage you to make a personal contribution with your research, the only way to sustain the reputation of our Society and the Journal.

Publisher's note: Springer Nature remains neutral with regard to jurisdictional claims in published maps and institutional affiliations.

\section{References}

1. Beevers DG, Messerli FH. Hypertension-moving toward the year 2000. J Hum Hypertens. 1987;1:1-2.

2. Beevers DG, Messerli FH, Ueshima H. The Journal of Human Hypertension: looking back over 10 years of research and thinking of the future. J Hum Hypertens. 1997;11:1-5.

3. Stowasser M. JHH change in leadership. J Hum Hypertens. 2015;29:399. 